\title{
Comparison of Stereotactic Aspiration, Craniotomy, and Conservative Treatment for Putaminal Hemorrhage
}

\author{
Ryuya YAMANAKA and Susumu SATOH
}

Department of Neurosurgery, Yamagata Prefectural Central Hospital, Yamagata

\begin{abstract}
The results of stereotactic aspiration, conventional craniotomy, and conservative treatment were compared in 91 cases of putaminal hemorrhage, all involving a medium-sized hematoma $(20-60 \mathrm{ml})$. The average interval between onset of symptoms and operation was 7.4 days for stereotactic aspiration and 11.5 hours for craniotomy. Patients with low neurological grades and low computed tomography (CT) classifications had better outcomes regardless of treatment. Among patients with a neurological grade of 3 , the outcome was significantly poorer with conservative treatment than with stereotactic aspiration or conventional craniotomy ( $\mathrm{p}<0.05$ ). Among grade 4 a patients, conventional craniotomy yielded the best results $(\mathbf{p}<0.05)$. Among those with CT classifications III and IVa, the outcome was significantly poorer with conservative treatment than with stereotactic aspiration or conventional craniotomy $(\mathrm{p}<0.05)$.
\end{abstract}

Key words: putaminal hemorrhage, stereotactic aspiration, craniotomy, neurological grading

\section{Introduction}

Stereotactic aspiration, which does not require general anesthesia, has gained wide acceptance in the treatment of hypertensive intracerebral hemorrhage. ${ }^{1,6,7)}$ However, the indications for this procedure remain controversial. Moreover, there have been no reports of detailed comparisons of the results of stereotactic aspiration with those of conventional craniotomy or conservative treatment approaches. We retrospectively evaluated the results of these three approaches in 91 patients treated for putaminal hemorrhage during the last 8 years. All had mediumsized hematomas (i.e., the hematoma volume was 20-60 ml), for which the selection of appropriate treatment is difficult. We describe the results and offer guidelines for the treatment of putaminal hemorrhage, giving special attention to the indications for stereotactic aspiration.

\section{Patients and Methods}

172 patients were diagnosed by computed tomography $(C T)$ as having a putaminal hemorrhage. Of these, 91 had hematoma volumes ranging from 20 to $60 \mathrm{ml}$. Thirty-one were treated by stereotactic aspiration (Group A), 36 underwent craniotomy (Group B), and 24 were treated conservatively (Group C). Table 1 provides a clinical summary of the patient population by treatment group. There were no significant intergroup differences in age, sex, or hematoma volume. The CT classifications and neurological grades were similar among the three groups. A few patients in each group had histories of cardiovascular disease, diabetes mellitus, cancer, and/or heart disease. The nondominant hemisphere was more often affected in Group C. The average time intervals between the onset of symptoms and operation were 7.4 days in Group A and 11.5 hours in Group B. The average hematoma aspiration percent in Group A was $64.8 \%$.

All stereotactic aspirations were performed under local anesthesia. In 18 cases the apparatus designed at Niigata University in 1973 (Shindai's method ${ }^{12)}$ ) was used, and in 13 cases Komai's method" was employed. The outer diameters of the aspiration tubes were 1.0 and $2.5 \mathrm{~mm}$, respectively. After aspiration of the liquid hematoma portion, a silicon tube was inserted through the original track and left in the hematoma cavity. The residual hematoma was

Received December 1, 1986; Accepted February 16, 1988

Author's present address: R. Yamanaka, M.D., Department of Neurosurgery, Brain Research Institute, Niigata University, Niigata, Japan. 
Table 1 Clinical summary of patients with putaminal hemorrhage

\begin{tabular}{|c|c|c|c|}
\hline & $\begin{array}{l}\text { Stereotactic } \\
\text { aspiration } \\
(\mathrm{n}=31)\end{array}$ & $\begin{array}{l}\text { Crani- } \\
\text { otomy } \\
(\mathrm{n}=36)\end{array}$ & $\begin{array}{c}\text { Conserva- } \\
\text { tive } \\
\text { treatment } \\
(\mathbf{n}=24)\end{array}$ \\
\hline Age (years) & $61.1 \pm 11.4$ & $58.5 \pm 8.96$ & $64.4 \pm 9.57$ \\
\hline Sex ratio $(M / F)$ & 1.38 & 1.57 & 1.38 \\
\hline $\begin{array}{l}\text { Hematoma } \\
\quad \text { volume }(\mathrm{ml})\end{array}$ & $30.4 \pm 10.6$ & $38.1 \pm 10.8$ & $37.2 \pm 15.0$ \\
\hline $\begin{array}{l}\text { Side } \\
\quad \text { (dominant/ } \\
\text { nondominant) }\end{array}$ & 1.06 & 1.0 & 0.56 \\
\hline $\begin{array}{l}\text { Interval from onset } \\
\text { to operation }\end{array}$ & $\begin{array}{c}7.4 \pm 6.2 \\
\text { days }\end{array}$ & $\begin{array}{c}11.5 \pm 10.8 \\
\text { hours }\end{array}$ & - \\
\hline $\begin{array}{l}\text { Hematoma } \\
\text { aspiration } \\
\text { percent }\end{array}$ & $64.8 \pm 21.5 \%$ & - & - \\
\hline \multicolumn{4}{|l|}{ CT classification* } \\
\hline I & 1 & 0 & 4 \\
\hline II & 4 & 4 & 4 \\
\hline III & 18 & 19 & 10 \\
\hline IV & 7 & 13 & 6 \\
\hline $\mathrm{V}$ & 1 & 0 & 0 \\
\hline \multicolumn{4}{|l|}{ Neurological grade* } \\
\hline 1 & 6 & 3 & 5 \\
\hline 2 & 14 & 12 & 7 \\
\hline 3 & 10 & 13 & 7 \\
\hline 4 & 1 & 8 & 5 \\
\hline 5 & 0 & 0 & 0 \\
\hline \multirow{4}{*}{$\begin{array}{l}\text { Medical history } \\
\text { (no. of cases) }\end{array}$} & CVD (4) & CVD (2) & CVD (3) \\
\hline & DM (1) & & DM (1) \\
\hline & $\begin{array}{l}\text { colon } \\
\text { cancer (1) }\end{array}$ & & $\begin{array}{l}\text { lung } \\
\text { cancer (1) }\end{array}$ \\
\hline & AMI (1) & & $\begin{array}{l}\text { heart } \\
\text { failure (1) }\end{array}$ \\
\hline
\end{tabular}

*According to Kanaya et al. ${ }^{3\}}$ CVD: cerebrovascular disease, DM: diabetes mellitus, AMI: acute myocardial infarction.

dissolved by urokinase and drained over the next several days.

All microsurgical evacuations through craniotomy were performed under general anesthesia by the trans-Sylvian approach. ${ }^{8}$ The indication for surgery was decided by the surgeon in charge, as no criteria had been established by the hospital.

From 1979 through 1982 the preferred surgical approach was craniotomy, whereas stereotactic aspiration was more frequently performed from 1983 through 1986.

Conservative treatment consisted of steroid hormones, glycerol, and mannitol, and other appropriate agents, administered as needed.

The preoperative neurological grade and CT classification were determined according to the criteria of the Japanese Ad Hoc Committee on Hypertensive Intracerebral Hemorrhage proposed in 1978. ${ }^{3)}$ The outcome is expressed in terms of mortality and activities of daily living 6 months after the onset of illness. ${ }^{2)}$ A "good" result denotes ability to work full time and/or complete self sufficiency, "fair" indicates partial dependency, and "poor" designates confinement to bed or vegetative status.

\section{Results}

Tables 2 and 3 list the outcomes for each treatment group by neurological grade and CT classification. Altogether there were 17 deaths - two in Group A, five in Group B, and 10 in Group C. The posttreatment complications and causes of death are listed in Table 4. The incidence of complications was significantly lower in Group A $(19 \%)$ than in Groups B $(42 \%)$ and C $(42 \%)(\mathrm{p}<0.05)$.

As Table 2 shows, the higher the neurological grade the poorer the outcome. All of the grade $4 \mathrm{~b}$ patients and nearly one half of the grade 4a patients died. Among the grade 4a patients, those in Group B had the best results $(p<0.05)$. Among those of grade 3 , the outcome was significantly poorer in Group C than in Group A or B $(p<0.05)$; there was no significant difference between Groups A and B. The distribution of grades 1 and 2 was nearly equal among the three groups, and there were no significant intergroup differences in outcome within these two neurological grades.

Among patients with CT classifications III and IVa, the outcome was significantly poorer in Group $C$ than in Group A or B $(p<0.05)$ (Table 3). The clinical outcomes of the patients who underwent stereotactic aspiration within 3 days of the onset of hemorrhage were compared with the outcomes of patients for whom the procedure was delayed. Among patients of neurological grades 2 and 3 , the outcome bore no relationship to the interval between onset of symptoms and aspiration of the hematoma (Table 5).

\section{Discussion}

With CT, the location, extent, and volume of hematomas can be accurately determined, and so we have seen an increase in the use of stereotactic aspiration. ${ }^{1,5-7,12)}$ The main advantage of aspiration is that it can be performed under local anesthesia and thus expands the treatment options for patients in whom general anesthesia is often contraindicated, including the elderly and those with serious medical complications. ${ }^{1,6,12)}$ Stereotactic aspiration has attracted a 
Table 2 Outcome by neurological grade and treatment

\begin{tabular}{|c|c|c|c|c|c|c|}
\hline \multirow{2}{*}{$\begin{array}{l}\text { Neurological } \\
\text { grade }\end{array}$} & \multirow{2}{*}{ Treatment } & \multirow{2}{*}{$\begin{array}{l}\text { No. of } \\
\text { cases }\end{array}$} & \multicolumn{4}{|c|}{ Outcome } \\
\hline & & & Good & Fair & Poor & Death \\
\hline \multirow[t]{3}{*}{1} & stereotactic aspiration & 6 & $3(50 \%)$ & $2(33 \%)$ & 0 & $1(17 \%)$ \\
\hline & craniotomy & 3 & $2(67 \%)$ & $1(33 \%)$ & 0 & 0 \\
\hline & conservative treatment & 5 & $4(80 \%)$ & 0 & 0 & $1(20 \%)$ \\
\hline \multirow[t]{3}{*}{2} & stereotactic aspiration & 14 & $5(36 \%)$ & $8(57 \%)$ & $1(7 \%)$ & 0 \\
\hline & craniotomy & 12 & $5(42 \%)$ & $6(50 \%)$ & 0 & $1 \quad(8 \%)$ \\
\hline & conservative treatment & 7 & $4(57 \%)$ & $2(29 \%)$ & $1(14 \%)$ & 0 \\
\hline \multirow[t]{3}{*}{3} & stereotactic aspiration & 10 & $3(30 \%)$ & $6(60 \%)$ & 0 & $1(10 \%)$ \\
\hline & craniotomy & 13 & $4(31 \%)$ & $6(46 \%)$ & $1 \quad(8 \%)$ & $2(15 \%)$ \\
\hline & conservative treatment & 7 & 0 & $2(29 \%)$ & $1(14 \%)$ & $4(57 \%)$ \\
\hline \multirow[t]{3}{*}{$4 a$} & stereotactic aspiration & 1 & 0 & 0 & $1(100 \%)$ & 0 \\
\hline & craniotomy & 8 & $2(25 \%)$ & $2(25 \%)$ & $2(25 \%)$ & $2(25 \%)$ \\
\hline & conservative treatment & 3 & 0 & 0 & 0 & $3(100 \%)$ \\
\hline \multirow[t]{3}{*}{$4 b$} & stereotactic aspiration & 0 & 0 & 0 & 0 & 0 \\
\hline & craniotomy & 0 & 0 & 0 & 0 & 0 \\
\hline & conservative treatment & 2 & 0 & 0 & 0 & $2(100 \%)$ \\
\hline
\end{tabular}

Table 3 Outcome by CT classification and treatment

\begin{tabular}{|c|c|c|c|c|c|c|}
\hline \multirow{2}{*}{$\underset{\text { classification }}{\mathrm{CT}}$} & \multirow{2}{*}{ Treatment } & \multirow{2}{*}{$\begin{array}{l}\text { No. of } \\
\text { cases }\end{array}$} & \multicolumn{4}{|c|}{ Outcome } \\
\hline & & & Good & Fair & Poor & Death \\
\hline \multirow[t]{3}{*}{ I } & stereotactic aspiration & 1 & $1(100 \%)$ & 0 & 0 & 0 \\
\hline & craniotomy & 0 & 0 & 0 & 0 & 0 \\
\hline & conservative treatment & 4 & $3(75 \%)$ & 0 & 0 & $1(25 \%)$ \\
\hline \multirow[t]{3}{*}{ II } & stereotactic aspiration & 4 & $3(75 \%)$ & $1(25 \%)$ & 0 & 0 \\
\hline & craniotomy & 4 & $3(75 \%)$ & $1(25 \%)$ & 0 & 0 \\
\hline & conservative treatment & 4 & $3(75 \%)$ & $1(25 \%)$ & 0 & 0 \\
\hline \multirow[t]{3}{*}{ III } & stereotactic aspiration & 18 & $6(33 \%)$ & $10(56 \%)$ & $1(5.5 \%)$ & $1 \quad(5.5 \%)$ \\
\hline & craniotomy & 19 & $7(37 \%)$ & $8(42 \%)$ & $1(5 \%)$ & $3(16 \%)$ \\
\hline & conservative treatment & 10 & $2(20 \%)$ & $2(20 \%)$ & $2(20 \%)$ & $4(40 \%)$ \\
\hline \multirow[t]{3}{*}{ IVa } & stereotactic aspiration & 5 & $1(20 \%)$ & $3(60 \%)$ & $1(20 \%)$ & 0 \\
\hline & craniotomy & 11 & $3(27 \%)$ & $5(46 \%)$ & $1(9 \%)$ & $2(18 \%)$ \\
\hline & conservative treatment & 4 & 0 & $1(25 \%)$ & 0 & $3(75 \%)$ \\
\hline \multirow[t]{3}{*}{$\mathrm{IVb}$} & stereotactic aspiration & 2 & 0 & $1(50 \%)$ & 0 & $1(50 \%)$ \\
\hline & craniotomy & 2 & 0 & $1(50 \%)$ & $1(50 \%)$ & 0 \\
\hline & conservative treatment & 2 & 0 & 0 & 0 & $2(100 . \%)$ \\
\hline \multirow[t]{3}{*}{$\mathrm{V}$} & stereotactic aspiration & 1 & 0 & $1(100 \%)$ & 0 & 0 \\
\hline & craniotomy & 0 & 0 & 0 & 0 & 0 \\
\hline & conservative treatment & 0 & 0 & 0 & 0 & 0 \\
\hline
\end{tabular}

great deal of attention as a new treatment for hypertensive intracerebral hematoma. ${ }^{1,6)}$ However, the indications for this procedure have not been established, and to our knowledge it has not been compared, in terms of long-term effectiveness, with either conventional craniotomy or conservative therapy. Also, this technique has one clear drawback: its application is restricted in the acute stage because it is impossible to directly observe hemostasis and confirm the initial source of bleeding. In the study reported here, stereotactic aspiration was not superior to conventional craniotomy in terms of outcome.

Rebleeding may occur if stereotactic aspiration is performed soon after the onset of hemorrhage. Earlier, we reported two instances $(2.9 \%)$ of rebleeding among 69 patients who underwent stereotactic aspiration within 5-48 hours of the onset 
of hemorrhage. ${ }^{12)}$ Matsumoto et al. $^{6)}$ noted that, among 51 patients treated by aspiration within 8-44

Table 4 Incidence of complication and mortality

\begin{tabular}{|c|c|c|c|c|c|c|}
\hline \multirow[t]{2}{*}{ Complication } & \multicolumn{2}{|c|}{$\begin{array}{l}\text { Stereotactic } \\
\text { aspiration } \\
(\mathrm{n}=31)\end{array}$} & \multicolumn{2}{|c|}{$\begin{array}{l}\text { Craniotomy } \\
(\mathrm{n}=36)\end{array}$} & \multicolumn{2}{|c|}{$\begin{array}{c}\text { Conservative } \\
\text { treatment } \\
(n=24)\end{array}$} \\
\hline & Survived & Died & Survived & Died & Survived & Died \\
\hline Pneumonia & $2(6 \%)$ & $2(6 \%)$ & $5(14 \%)$ & $3(8 \%)$ & $2(8 \%)$ & $2(8 \%)$ \\
\hline GI bleeding & $2(6 \%)$ & - & $5(14 \%)$ & - & $4(17 \%)$ & - \\
\hline Heart failure & - & - & - & $1(3 \%)$ & - & $1(4 \%)$ \\
\hline Renal failure & - & - & - & - & - & $1(4 \%)$ \\
\hline $\begin{array}{c}\text { Fulminant } \\
\text { hepatitis }\end{array}$ & - & - & - & $1(3 \%)$ & - & - \\
\hline
\end{tabular}

GI: gastrointestinal.

Table 5 Interval from onset of symptoms to stereotactic aspiration and outcome

\begin{tabular}{|c|c|c|c|c|c|c|}
\hline \multirow{2}{*}{$\begin{array}{l}\text { Neurological } \\
\text { grade }\end{array}$} & \multirow{2}{*}{$\begin{array}{c}\text { Interval } \\
\text { from onset } \\
\text { to operation }\end{array}$} & \multirow{2}{*}{$\begin{array}{l}\text { No. of } \\
\text { cases }\end{array}$} & \multicolumn{4}{|c|}{ Outcome } \\
\hline & & & Good & Fair & Poor & Death \\
\hline 2 & early* & 3 & $1(33 \%)$ & $1(33 \%)$ & & 0 \\
\hline & delayed** & 11 & $4(36 \%)$ & $7(64 \%)$ & 0 & 0 \\
\hline 3 & $\begin{array}{l}\text { early* } \\
\text { delayed** }\end{array}$ & $\begin{array}{l}6 \\
4\end{array}$ & & & $\begin{array}{l}0 \\
0\end{array}$ & $\begin{array}{l}1(17 \%) \\
0\end{array}$ \\
\hline
\end{tabular}

${ }^{*}$ Early: 0-3 days, ${ }^{* *}$ delayed: 4 days or more. hours of basal ganglionic hemorrhage, two (3.9\%) had rebleeding. Based on observation of extravasation of contrast medium during angiography, Takada" concluded that most episodes of rebleeding occurred within 6-7 hours of the onset of intracerebral hemorrhage. For this reason we delayed the aspiration procedure for at least 24 hours after the hematoma had developed.

Vascular anomalies have been found in some patients with CT evidence of so-called "basal ganglionic hemorrhage." "11) These vascular anomalies are reportedly difficult to detect due to the pressure generated by the hematoma. In such cases, even though stereotactic aspiration is conducted 24 hours or more after the onset of hemorrhage, there is a danger of rebleeding.

The disruption of cerebral blood flow and disturbance in brain metabolism in the vicinity of a hematoma may lead to irreversible degeneration. ${ }^{13)}$ Therefore, it is important to rectify these disturbances as quickly as possible. In the study reported here, the outcome following hematoma aspiration was not improved by performing the procedure early. This suggests that it is possible to predict the outcome very soon after the onset of bleeding. In any event, with both craniotomy and stereotactic aspiration, the interval between onset of bleeding and

Table 6 Reported results of therapy for putaminal hemorrhage

\begin{tabular}{|c|c|c|c|c|c|c|c|}
\hline \multirow{2}{*}{$\begin{array}{l}\text { Neurological } \\
\text { grade }\end{array}$} & \multirow{2}{*}{ Authors (treatment) } & \multirow{2}{*}{$\begin{array}{l}\text { No. of } \\
\text { cases }\end{array}$} & \multicolumn{5}{|c|}{ Outcome (6 months after onset) } \\
\hline & & & Good & Fair & Poor & Death & Unknown \\
\hline \multirow[t]{4}{*}{2} & $\begin{array}{l}\text { Kaneko et al. }{ }^{41} \\
\text { (craniotomy) }\end{array}$ & 10 & $7(70 \%)$ & $2(20 \%)$ & 0 & $1(10 \%)$ & - \\
\hline & $\begin{array}{l}\text { Kanaya and Endo }{ }^{2)} \\
\text { (craniotomy) }\end{array}$ & 795 & $282(35.5 \%)$ & $188(23.6 \%)$ & $35(4.4 \%)$ & $75(9.4 \%)$ & $215(27.0 \%)$ \\
\hline & $\begin{array}{l}\left.\text { Matsumoto and Hondo }{ }^{6}\right) \\
\text { (stereotactic aspiration) }\end{array}$ & 24 & $12(50 \%)$ & $9(38 \%)$ & $1(4 \%)$ & $2(8 \%)$ & - \\
\hline & $\begin{array}{l}\text { Wage et al. }{ }^{10)} \\
\text { (conservative treatment) }\end{array}$ & 16 & $9(56 \%)$ & $4(25 \%)$ & $1(6 \%)$ & $2(13 \%)$ & - \\
\hline \multirow[t]{4}{*}{3} & $\begin{array}{l}\text { Kaneko et al. } \\
\text { (craniotomy) }\end{array}$ & 68 & $36(53 \%)$ & $25(37 \%)$ & $4(6 \%)$ & $3(4 \%)$ & - \\
\hline & $\begin{array}{l}\text { Kanaya and Endo } \\
\text { (craniotomy) }\end{array}$ & 899 & $212(23.6 \%)$ & $249(27.7 \%)$ & $87(9.7 \%)$ & $148(16.5 \%)$ & $203(22.6 \%)$ \\
\hline & $\begin{array}{l}\text { Matsumoto and Hondo } \\
\text { (stereotactic aspiration) }\end{array}$ & 23 & $9(39 \%)$ & $10(44 \%)$ & $1(4 \%)$ & $3(13 \%)$ & - \\
\hline & $\begin{array}{l}\text { Waga } e t \text { al. } \\
\text { (conservative treatment) }\end{array}$ & 21 & $6(29 \%)$ & $4(19 \%)$ & $5(24 \%)$ & $6(29 \%)$ & - \\
\hline \multirow[t]{4}{*}{$4 a$} & $\begin{array}{l}\text { Kaneko et al. } \\
\text { (craniotomy) }\end{array}$ & 18 & $7(39 \%)$ & $5(28 \%)$ & $6(33 \%)$ & 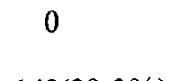 & - \\
\hline & $\begin{array}{l}\text { Kanaya and Endo } \\
\text { (craniotomy) }\end{array}$ & 488 & $68(13.9 \%)$ & $110(22.5 \%)$ & $72(14.8 \%)$ & $143(29.3 \%)$ & $95(19.5 \%)$ \\
\hline & $\begin{array}{l}\text { Matsumoto and Hondo } \\
\text { (stereotactic aspiration) }\end{array}$ & 10 & $1(10 \%)$ & $1(10 \%)$ & $5(50 \%)$ & $3(30 \%)$ & - \\
\hline & $\begin{array}{l}\text { Waga et al. } \\
\text { (conservative treatment) }\end{array}$ & 16 & $1(6 \%)$ & $3(19 \%)$ & $1(6 \%)$ & $11(69 \%)$ & - \\
\hline
\end{tabular}


operation appears to be important to the outcome.

Although stereotactic aspiration appears to have a lower incidence of complications, it should be remembered that this procedure has been in wide use only since 1983 , whereas craniotomy was the method of choice before 1983. The availability of $\mathrm{H}_{2}$ blockers and new antibiotics has markedly lowered the incidence of gastrointestinal bleeding following surgery and improved the prophylaxis and treatment of pneumonia. Other recent advances in postoperative care and improvements in general anesthesia should be taken into account in the selection of treatment for putaminal hemorrhage.

In the treatment of mild cases of hemorrhage (neurological grade 1 or 2), we found no notable differences among craniotomy, stereotactic aspiration, and conservative therapy. There have been reports $^{73}$ of rapid improvement of motor weakness after stereotactic aspiration of small hematomas. However, rapid improvement often occurs with conservative treatment as well. Therefore, the rationale for stereotactic aspiration of small hematomas should be clearly defined. A review of the relevant literature ${ }^{2,4,6,10)}$ suggests that in patients of neurological grade 1 or 2 , conservative treatment is sufficient (Table 6).

Regarding patients of neurological grade 3, Waga et $a l^{\left({ }^{10)}\right.}$ reported excellent results with conservative treatment. However, many Japanese neurosurgeons are of the opinion that, for patients of neurological grade 3 or $4 a$, surgery produces better results. Kaneko et al. ${ }^{4)}$ reported excellent results following microsurgical evacuation in the superacute stage (within 6-7 hours of the onset of bleeding). When the neurological grade is 3 or $4 \mathrm{a}$, hemostasis should be accomplished as soon as possible after the site of bleeding has been confirmed.

As a rule, stereotactic aspiration is considered an option for elderly patients and those for whom general anesthesia is not feasible because of complications. Patients whose hematoma volume is $20 \mathrm{ml}$ or less are considered neurological grade 1 or 2 and are usually treated conservatively, with good results. A hematoma volume of more than $60 \mathrm{ml}$ is assigned a neurological grade of at least 3. Conventional craniotomy is limited to neurological grades 3 and $4 a$; surgery is not applicable to hematomas of neurological grade $4 b$ or 5 .

\section{References}

1) Doi E, Moriwaki $\mathrm{H}$, Komai $\mathrm{N}$, Iwamoto $\mathrm{M}$ : Stereotactic evacuation of intracerebral hematomas. Neurol Med Chir (Tokyo) 22: 461-467, 1982 (in
Japanese)

2) Kanaya $H$, Endo $H$ : Surgical treatment and results of surgery for hypertensive intracerebral hemorrhage. No To Shinkei 36: 847-857, 1984 (in Japanese)

3) Kanaya H, Yukawa H, Itoh Z, Kagawa $Y$, Kanno $T$, Kuwabara T, Mizukami K: A neurological grading for patients with hypertensive intracerebral hemorrhage and a classification for hematoma location on computed tomography, in: Proceedings of the Seventh Conference of Surgical Treatment of Stroke. Tokyo, Neuron Co., 1978, pp 265-270 (in Japanese)

4) Kaneko $M$, Tanaka $K$, Shimada $T$, Sato $K$, Uemura $\mathrm{K}$ : Long-term evaluation of ultra-early operation for hypertensive intracerebral hemorrhage in 100 cases. $J$ Neurosurg 58: 838-842, 1983

5) Matsumoto K: Stereotactic hematoma aspiration for acute stage hypertensive intracerebral hemorrhage, in Hashi K, Saito I (eds): The Fourth Meeting of The Mt. Fuji Workshop on CVD, vol 4, Surgical Treatment for Hypertensive Intracerebral Hemorrhage. Tokyo, Kodama, 1986, pp 117-123 (in Japanese)

6) Matsumoto K, Hondo H: CT-guided stereotaxic evacuation of hypertensive intracerebral hematomas. $J$ Neurosurg 61: 440-448, 1984

7) Shichijo F, Matsumoto K: CT-controlled stereotactic operations for hypertensive intracerebral hemorrhage. Part 2: Cases of small hematomas in the thalamus and the basal ganglia. No Shinkei Geka 13: 945-952, 1985 (in Japanese)

8) Suzuki J, Sato S: The new trans-sylvian approach to the hypertensive intracerebral hematoma. Jpn J Surg 2: 47-52, 1972

9) Takada I: The phenomenon of extravasation of contrast medium in cerebral angiography in cases of hypertensive intracerebral hematoma and its clinical significance. Analysis of 14 cases. No Shinkei Geka 4 : 471-478, 1976 (in Japanese)

10) Waga S, Miyazaki $M$, Okada $M$, Tochio $H$, Matsushima S, Tanaka Y: Hypertensive putaminal hemorrhage: Analysis of 182 patients. Surg Neurol 26: $159-166,1986$

11) Yamada $T$, Sayama I, Nemoto $\mathbf{M}$ : Basal ganglia bleeding due to abnormal vessels, in Kitamura K (ed): Proceedings of the Eleventh Japanese Conference on Cerebral Stroke. Fukuoka, 1986, p 169

12) Yamanaka R, Sato S: Analysis of intra- and postoperative recurrent bleeding in cases of stereotactic hematoma aspiration. No Socchu 10: 54-59, 1988 (in Japanese)

13) Yoshida Y: Vascular changes in and around hematomas in the brain of patients with hypertensive intracerebral hemorrhage. Myakkangaku 21: 855857, 1981 (in Japanese)

Address reprint requests to: R. Yamanaka, M.D., Department of Neurosurgery, Brain Research Institute, Niigata University, 757 Ichiban-cho, Asahimachidori, Niigata 951, Japan. 